\title{
The decline in dental caries among Korean children aged 8 and 12 years from 2000 to 2012 focusing SiC Index and DMFT
}

\author{
Han-Na Kim', Dong-Hun Han², Eun-Joo Jun ${ }^{3}$, Se-Yeon Kim, ${ }^{3,4}$ Seung-Hwa Jeong ${ }^{3,4}$ and Jin-Bom Kim³ ${ }^{3,4^{*}}$
}

\begin{abstract}
Background: The aim of this study was to analyse the prevalence and severity of dental caries among Korean children aged 8 and 12 years over a period of 12 years by determining the number of decayed, missing, and filled teeth (DMFT) and the Significant Caries index (SiC index).

Methods: Stratified cluster-sampled data from the National Oral Health Survey conducted from 2000 to 2012 were analysed. In 2000, 2006, and 2012, a total of 2397, 2650, and 9601 children aged 8 and 12 years were examined, respectively. The children's oral health status, including the number of DMFT and fissures sealed teeth, was examined and recorded. The SiC index was calculated according to the child's residential district.

Results: Over the 12-year period, the percentages of caries-free children aged 8 and 12 years increased from 26.0 to $42.7 \%$ and from 53.4 to $69.6 \%$, respectively. The percentages of children aged 8 and 12 years with sealed teeth in 2012 were 62.1 and $62.5 \%$, respectively, more than triple the rates in 2000. The mean DMFT values of children aged 8 and 12 years decreased from 1.04 to 0.67 and from 2.86 to 1.84 , respectively. The $\mathrm{SiC}$ index of children aged 8 and 12 years also decreased from 2.73 to 1.97 and from 6.13 to 4.51, respectively. The rate of reduction in DMFT among 8- and 12-year-old children in the second 6 years of the observation period was lower than that in the first 6 years.

Conclusions: A remarkable decline in dental caries of 8- and 12-year-old Korean children was observed over the 12-year study period. The mean DMFT values and SiC index of children aged 8 and 12 years decreased. The reduction rate between 2000 and 2006 was higher than that between 2006 and 2012.
\end{abstract}

Keywords: Children, Dental caries, Decayed, missing, and filled teeth, Significant caries index

\section{Background}

Dental caries can have a negative impact on children's quality of life [1]. Sheiham [2] reported that severe dental caries affect young children's growth and hypothesised that improving dietary intake and treating dental caries in pre-school-aged children would increase growth rates and improve quality of life. To monitor

\footnotetext{
* Correspondence: jbomkim@pusan.ac.kr

${ }^{3}$ Department of Preventive and Community Dentistry, Pusan National University, School of Dentistry, 49, Busandaehak-ro, Mulgeum-eup, Yangsan-si, Gyeongsangnam-do, 626-870 Seoul, Korea

${ }^{4}$ BK Plus Project of Center of Center for Professional Education on Technosciences of Oral Health, Seoul, Korea

Full list of author information is available at the end of the article
}

dental caries in children, the World Health Organization (WHO) developed an oral disease surveillance system. The first global map with data related to decayed, missing, and filled teeth (DMFT) for 12-year-olds was presented in 1969 [3]. There has been an overall decline in the prevalence and severity of dental caries in children and adolescents around the world, particularly in developed countries [4]. In spite of this overall decline, scores or indices expressing the prevalence of dental caries have varied. A previous study reported differences in the prevalence of dental caries in permanent teeth between 2000 and 2010. The numbers of DMFT in 12-year-olds were 2.96, 2.07, 0.89, and 0.70 in the Czech Republic, 
Brazil, Denmark, and Germany, respectively [5]. Some studies have demonstrated inequalities in the distribution of dental caries [6-8]. Socioeconomic factors, such as access to oral health care, can contribute to these inequalities [9].

The use of DMFT data is an accepted approach for assessing the severity and prevalence of dental caries as well as for assessing overall oral health [10]. However, skewed distributions of caries prevalence have been reported in many countries. Ditmyer et al. [11] reported that the mean number of DMFT did not accurately reflect the skewed distribution of dental caries in youth in Nevada, leading to incorrect conclusions. The Significant Caries index ( $\mathrm{SiC}$ index) was proposed as a means to highlight individuals with the highest caries scores in each population $[12,13]$.

Since the Oral Health Act for oral health promotion was passed by the National Assembly of the Republic of Korea in 2000, public oral health programmes have been developed to reduce the incidence of dental caries. In Korea, there is a legal basis for supporting oral health programmes; the development of specific public oral health programmes by municipal authorities is required by the Oral Health Act. The Health Promotion Act states that health information and healthy environments should be provided to promote general health. The operation of public health centres and the installation of regional health centres were included in the Regional Health Act [14]. Public oral health programmes comprising community water fluoridation, fluoride mouth rinsing, and a fissure sealant program were the primary programmes for preventing dental caries in urban and rural areas [15]. Kim and Jeon [16] showed that the DMFT values in 12-year-olds had declined and that general oral health had improved but that its inequality had increased. Several studies using cross-sectional or other designs have reported data related to Korean children's oral health using DMFT values $[17,18]$ and the $\mathrm{SiC}$ index [19] to express the inequality of oral health [16]. In this study, we used a simple index based on the number of DMFT, the SiC index, and the SiC index/ DMFT ratio to express disparities in the incidence of dental caries. Because the $\mathrm{SiC}$ index/DMFT ratio is calculated as the $\mathrm{SiC}$ index divided by the DMFT score, it can be used as a novel expression of the severity of dental caries for groups based on region or community. For example, if the mean number of DMFT declines but the prevalence of severe dental caries based on the $\mathrm{SiC}$ index remains high, the $\mathrm{SiC} /$ DMFT ratio would increase. Thus, the $\mathrm{SiC}$ index/ DMFT ratio can show disparities in the prevalence of dental caries for high-risk groups. The aim of the present study was to analyse the prevalence and severity of dental caries in 8- and 12-year-old Korean children over a period of 12 years by measuring the number of DMFT and determining the $\mathrm{SiC}$ index.

\section{Methods \\ General characteristics related to oral health in Korea}

The population increases between 2000 and 2006 was $2.7 \%$, and its increase between 2006 and 2012 was $3.5 \%$. More than 50 million people lived in Korea in 2012. The gross domestic product (GDP) increased in 2012 from that in 2006. Less than $10 \%$ of the GDP total expenditures was spent on health. The number of practicing dentists in 2000 was 17,647 . The number of practicing dentists in Korea increased by $28.5 \%$ in 2006 compared to that in 2000 and by $18.2 \%$ in 2012 compared to that in 2006. Since 1979, the Korean government has placed dentists in rural areas where the private dental care system was inferior. The percentage of the Korean population covered by the water fluoridation programme that began in 1981 [20] decreased from 12.7 to $6.1 \%$ between 2000 and 2012. The decline was caused by a movement banning fluoridation since 1998. A fluoride mouth-rinsing programme was begun in 1983, and a free fissure sealant programme that was implemented by the government from 2002 to 2009 was conducted for almost 200,000 primary school children every year by public health centres. Fissure sealant has been covered for children by national health insurance since 2009 . The scope of oral health in public health care has expanded since 2005. Facilities for tooth-brushing drills in primary schools were installed beginning in 2011 (Table 1). Because a previous study reported that more than $97 \%$ of metropolitan citizens used fluoridated toothpaste [21], it was assumed that the majority of Korean people used fluoridated toothpaste and that the toothpaste had preventive effects against dental caries.

\section{Subjects}

The National Oral Health Survey has been conducted every 3 years by the Ministry of Health and Welfare based on the Oral Health Act legislated by the National Assembly of the Republic of Korea in 2000 [22, 23]. The aim of the survey is to collect representative oral health data for the establishment of public oral health policy [23]. To promote the oral health of all Korean people, enforced by the regulations of the Oral Health Act, a survey of the population's oral health status should be conducted by the Ministry of Health and Welfare. Based on the Oral Health Act, ethics committee approval was not needed. Written consents were obtained from participants and their parents. The data of national oral health survey can be obtained from the Korea Health Promotion Foundation [24] by sending an e-mail with a 
Table 1 General features of Korea and the characteristics of oral health services

\begin{tabular}{|c|c|c|c|c|c|}
\hline & 2000 & 2006 & 2012 & $\%$, Change ${ }^{b}$ & $\%$, Change ${ }^{c}$ \\
\hline Population (thousands persons) & 47,008 & 48,297 & 50,004 & 2.7 & 3.5 \\
\hline 0 to 14 years old & 9,911 & 8,996 & 8,422 & -9.2 & -6.4 \\
\hline Health expenditure/GDP (\%) & 4.8 & 6.0 & $7.4^{\mathrm{a}}$ & 25.0 & 23.3 \\
\hline \multicolumn{6}{|l|}{ Total expenditure on health (\% GDP) } \\
\hline Practicing dentists (persons) & 14,410 & 18,515 & 21,888 & 28.5 & 18.2 \\
\hline Population drinking fluoridated water (\%) & 12.7 & 5.8 & 6.4 & -54.3 & 10.3 \\
\hline Population received public fissure sealant program aged 12 year & & 34.0 & 62.54 & - & 83.9 \\
\hline
\end{tabular}

a Indicated data in 2011

b Results from (2006-2000)/2000

c Results from (2012-2006)/2006

written application. Children aged 8 and 12 years were included in the surveys in 2000, 2006, and 2012.

\section{Sampling}

Children's oral health statuses varied based on socioeconomic status (SES) and living environment, and living standards could vary according to the size of counties, cities, and metropolitan areas. Therefore, a population size was classified by county, city, and metropolitan area.

Samples were selected using a stratified clustersampling procedure based on a population and housing census in order to represent all Korean children. The surveyed areas also included counties, cities, and metropolitan areas. The distribution of primary schools was determined by the results of the sample allocation. After allocation, one school located in each surveyed district was selected as a representative school. Consequently, the numbers of selected schools were 200, 150, and 190 in 2000, 2006, and 2012, respectively. The National Oral Health Survey for schoolchildren was conducted through school visits.

The sampling frame for the 2000 survey was the list of schools from the 200 survey districts maintained by the Department of Statistics. Children and adolescents aged 6 to 17 years from primary, junior, and high schools in the 200 surveyed districts were selected randomly from a list according to the surveyed districts. The total number of subjects was 11947 , and the numbers of subjects aged 8 and 12 years were 1194 and 1203, respectively. After one classroom of each school's grade was randomly selected, every fifth child in the selected classroom was examined by stratified clustering [25].

The sampling frame for the 2006 survey was the same as that for the 2000 survey, except for the number of surveyed districts and subjects in the focus age group. In the 2006 survey, 2- to 16-year-old children and adolescents (10 649 subjects) were included in the oral survey. Among the total number of subjects, the numbers of 8 - and 12year-old children were 875 and 1775 , respectively. The number of surveyed districts changed to 150 , and the number of sampled 12-year-olds was intentionally twice as high as that of the other age groups [26].

The number of surveyed districts changed to 190 and subjects comprised 5-, 8-, 12-, and 15-year-old children in the 2012 survey. The sampling frame for the 2012 survey was the same as that for the 2000 and 2006 survey. The proportional distribution based on the total population scale was applied to allocate 190 districts according to each city and prefecture, then to subgrouping, and it was also applied to each city and prefecture. Each kindergarten, primary, junior, and high school in the 190 survey districts was selected randomly from a list dividing all the schools according to the survey districts [27]. In Korea, almost all primary schools are operated by the government; thus, there were few socioeconomic differences in the educational conditions among sampled schools.

\section{Oral examination and data collection}

The survey was conducted with the cooperation of the Department of Education in each survey district. Prior to the survey, principals of selected schools received a letter requesting their cooperation, and questionnaires were sent out for completion and parents' agreement.

Fifteen survey teams composed of university staff majoring in preventive dentistry in dental schools and dental hygiene schools joined in the 2000 survey. All oral status examiners were dentists who worked as professors or assistants in universities. For the 2006 survey, eight teams composed of public health dentists and university staff majoring in preventive dentistry in dental schools and dental hygiene schools joined the survey. For the 2012 survey, 10 teams were composed of two public health dentists and eight university staff members from dental schools. Each team in the 2000, 2006, and 2012 survey contained a dentist and an interview expert [28].

The oral examinations were performed in the classroom, with children sitting facing a window with a portable blue-white colour spectrum examination light. The 
diagnostic criteria followed the WHO protocol [29]. Dental caries were recorded as $\mathrm{D}_{3}$ caries into the dentine threshold. Teeth showing sealed fissures were identified as being either complete or incomplete. Examinations were performed using disposable instruments: plane mirrors, sharp explorers, and ball-ended Community Periodontal Index probes. Radiographs were not used for diagnosis.

To control the quality of the national oral health examination, calibration training was conducted before each survey. After the principal investigator and examiners performed oral examinations on the same subjects, they discussed any different findings. An examiner was accepted to the survey when inter-examiner variability was acceptable and the findings showed good agreement with those of the principal investigator (kappa $\geq 0.7$ ).

\section{Statistical analysis}

The mean number of DMFT and the prevalence of caries in permanent teeth were calculated based on the clinical examination during the 2000, 2006, and 2012 surveys. The prevalence of caries-free $(\mathrm{DMFT}=0)$ and fissures sealed (individuals with pit and fissure sealants) was also calculated. The $\mathrm{SiC}$ index was calculated as the mean DMFT value for the one-third of the population with the highest caries scores.

The mean number of DMFT number and the $\mathrm{SiC}$ index were used as dependent variables. Age and area of residence were included as independent variables. To measure any inequality related to children's oral health, the $\mathrm{SiC}$ index/DMFT ratio was used [28]. A univariate analysis was performed to determine frequencies and mean values. The level of significance was set at $p<0.05$.

\section{Results}

Table 2 shows the number of subjects, percentage of caries-free children, and percentage of children with sealed teeth. In 2000, 2006, and 2012, a total of 2397, 2650, and 9601 children aged 8 and 12 years were examined, respectively.

The percentages of caries-free children aged 8 years increased from 53.4 to $69.6 \%$ between 2000 and 2012 $(p<0.05)$. The percentage of caries-free children aged 8 years was the highest in rural areas in 2012 (76.3\%). Overall, the percentages of caries-free children aged 8 years were lower in urban areas than in rural areas, but not significantly so. The percentage of 8-year-old children with sealed teeth increased from 19.2 to $62.1 \%$ from 2000 to $2012(p<0.001)$. The percentage of 8-year-old children with sealed teeth in rural area $(51.4 \%)$ was higher than that in urban area $(35.3 \%)$ in $2006(p<0.001)$.

Over the 12-year study period, the percentage of caries-free 12-year-old children increased from 26.0 to $42.7 \%$. For the same age group, the percentage of children with sealed teeth in 2012 was $62.5 \%$. Compared

Table 2 Prevalence of caries experience and fissure sealant in Korea 2000-2012 by age

\begin{tabular}{|c|c|c|c|c|c|c|c|c|c|c|c|}
\hline \multirow[t]{2}{*}{ Year } & \multirow[t]{2}{*}{ Living region } & \multicolumn{5}{|c|}{ Age 8} & \multicolumn{5}{|l|}{ Age 12} \\
\hline & & $\mathrm{N}$ & DMFT $=0, \%$ & $P^{*}$ & Sealed, $\%$ & $P^{*}$ & $\mathrm{~N}$ & DMFT $=0, \%$ & $P^{*}$ & Sealed, \% & $P^{*}$ \\
\hline \multirow[t]{3}{*}{2000} & Total & 1194 & 53.4 & 0.67 & 19.2 & 0.877 & 1203 & 26.0 & 0.006 & 14.8 & 0.011 \\
\hline & Urban & 780 & 52.9 & & 19.4 & & 784 & 28.6 & & 16.7 & \\
\hline & Rural & 414 & 54.3 & & 18.8 & & 419 & 21.2 & & 11.2 & \\
\hline \multirow[t]{3}{*}{2006} & Total & 875 & 69.5 & 1.00 & 38.6 & $<0.001$ & 1775 & 39.1 & 0.041 & 33.0 & 0.237 \\
\hline & Urban & 694 & 69.5 & & 35.3 & & 1386 & 40.4 & & 33.8 & \\
\hline & Rural & 181 & 69.6 & & 51.4 & & 369 & 34.1 & & 30.4 & \\
\hline \multirow[t]{5}{*}{2012} & Total & 4379 & 69.6 & 0.559 & 62.1 & 0.367 & 5222 & 42.7 & 0.612 & 62.5 & 0.438 \\
\hline & Urban & 3781 & 69.2 & & 62.3 & & 4565 & 42.8 & & 63.0 & \\
\hline & Rural & 598 & 76.3 & & 58.3 & & 657 & 41.0 & & 55.4 & \\
\hline & P-value** & & & & & & & & & & \\
\hline & & & $\mathrm{DMFT}=0, \%$ & & Sealed, $\%$ & & & DMFT $=0, \%$ & & Sealed, \% & \\
\hline \multirow[t]{3}{*}{$2000-2006$} & Total & & $<0.001$ & & $<0.001$ & & Total & $<0.001$ & & $<0.001$ & \\
\hline & Urban & & $<0.001$ & & $<0.001$ & & Urban & $<0.001$ & & $<0.001$ & \\
\hline & Rural & & $<0.001$ & & $<0.001$ & & Rural & $<0.001$ & & $<0.001$ & \\
\hline \multirow[t]{3}{*}{$2006-2012$} & Total & & 0.034 & & $<0.001$ & & Total & $<0.001$ & & $<0.001$ & \\
\hline & Urban & & 0.08 & & $<0.001$ & & Urban & 0.044 & & $<0.001$ & \\
\hline & Rural & & 0.158 & & $<0.001$ & & Rural & $<0.001$ & & $<0.001$ & \\
\hline
\end{tabular}


to that in 2000, it had increased fourfold. The percentage of caries-free children was higher in urban areas than in rural areas in all three surveys. The average annual increases in the percentages of caries-free children from 2000 to 2006 were $12-13 \%$, while the increases in the subsequent six years were lower, at 3-6\%.

Table 3 shows the DMFT and $\mathrm{SiC}$ index results. Over time, both values decreased for all ages. The mean number of DMFT for children aged 8 years in 2000 (1.04) was significantly lower than that in 2006 (0.68; $p<0.001)$, while the mean DMFT index in 2012 (0.67) decreased slightly compared to the mean in $2006(0.68 ; p=0.207)$. Between 2000 and 2006, the reduction rate of the number of DMFT $(50.55 \%)$ was higher in rural areas among children aged 8 years than in urban areas. The mean $\mathrm{SiC}$ index of 8-yearold children also decreased significantly (from 2.73 to 2.02) between 2000 and 2006. However, the mean SiC index seemed to be similar between 2006 and 2012, and there was no statistically significant difference.

Twelve-year-old children showed the same trends. The mean DMFT index of children aged 12 years consistently decreased, from 2.86 to 2.16 and finally to 1.84 , over the 12-year period $(p<0.05)$. The reduction rates of the mean DMFT index among 12-year-old children were 12.9 to $35.6 \%$ compared to the past 6 years $(p<0.05)$. Similar decreases were found for the $\mathrm{SiC}$ indices of 12 year-old children. The $\mathrm{SiC}$ indices of 12 -year-old children decreased from 6.13 to $4.51(p<0.05)$ during the 12 -year period. However, the reduction rate between 2000 and 2006 was higher than that between 2006 and 2012.

Figure 1 shows that the $\mathrm{SiC}$ index/DMFT ratios of children aged 12 years in 2006 and 2012 were higher than those in 2000. The $\mathrm{SiC}$ index/DMFT ratios in 2006 and 2012 were similar for children 12 years.
Figure 2 shows the DMFT scores across the different ranges of $\mathrm{SiC}$ index values and the number of each decayed, missing, and filled teeth in children aged 12 years. As the DMFT scores decreased from 6.16 to 4.68 , the number of missing and decayed teeth decreased while the number of filled teeth increased, from 3.91 to 4.18 .

\section{Discussion}

The results of this study show that the prevalence and severity of dental caries in Korean 8- and 12-year-old children declined between 2000 and 2012, according to national oral health data collected from a large nationally representative sample.

The percentage of caries-free children aged 12 years increased from 26.0 to $42.7 \%$ over 12 years, and the majority of this increase occurred in the first 6 years. These findings are in agreement with the results of Lee and Han [30], who reported that the prevalence of caries decreased from 75.9 to $60.5 \%$ in 12-year-olds between 2003 and 2010. Park et al. [31] demonstrated that the improvement in children's oral health was attributable to the public fissure sealant programme in Korea as well as to improvements in living standards and health behaviour during these first 6 years. The relatively lower increase in the number of caries-free children between 2006 and 2012 may be related to slow economic growth [32] and the fact that the Department of Oral Health in the Ministry of Health and Welfare was established in 1997 but abolished in 2007. The abolishment of the Department of Oral Health in the Ministry of Health and Welfare indicates that there had not been additional public health programmes developed to improve children's oral health. Eaton et al. [33] reported that dental hygienists were more frequently employed in some countries (Denmark, Finland, Iceland, the Netherlands, Norway,

Table 3 Change of the mean DMFT and SiC indices of Korea 2000-2012 by age

\begin{tabular}{|c|c|c|c|c|c|c|c|c|c|c|c|c|c|c|}
\hline \multirow[t]{2}{*}{ Age } & & \multicolumn{3}{|l|}{2000} & \multicolumn{3}{|l|}{2006} & \multicolumn{3}{|l|}{$2012^{a}$} & \multicolumn{2}{|c|}{ Reduction rate $^{\mathrm{b}}, \%$} & \multicolumn{2}{|c|}{ Reduction rate ${ }^{c}, \%$} \\
\hline & & $\overline{\mathrm{DMFT}}$ & $\mathrm{SiC}$ & $\overline{\mathrm{SiC} / \mathrm{DMFT}}$ & $\overline{\mathrm{DMFT}}$ & $\mathrm{SiC}$ & $\overline{\mathrm{SiC} / \mathrm{DMFT}}$ & $\overline{\mathrm{DMFT}}$ & $\mathrm{SiC}$ & $\overline{\mathrm{SiC} / \mathrm{DMFT}}$ & $\overline{\mathrm{DMFT}}$ & $\mathrm{SiC}$ & $\overline{\mathrm{DMFT}}$ & $\mathrm{SiC}$ \\
\hline \multirow[t]{3}{*}{8} & Total & 1.04 & 2.73 & 2.63 & 0.68 & 2.02 & 2.97 & 0.67 & 1.97 & 2.94 & -35.58 & -27.84 & -1.47 & -2.48 \\
\hline & Urban & 1.12 & 2.93 & 2.62 & 0.69 & 2.08 & 3.01 & 0.68 & 2.00 & 2.94 & -39.29 & -31.74 & -1.45 & -3.85 \\
\hline & Rural & 0.91 & 2.36 & 2.59 & 0.61 & 1.85 & 3.03 & 0.45 & 1.43 & 3.18 & -50.55 & -39.41 & -26.23 & -22.70 \\
\hline \multicolumn{2}{|c|}{ P-value* } & 0.015 & 0.544 & & 0.437 & $<0.001$ & & 0.162 & 0.823 & & & & & \\
\hline \multirow[t]{3}{*}{12} & Total & 2.86 & 6.13 & 2.14 & 2.16 & 5.16 & 2.39 & 1.84 & 4.51 & 2.45 & -35.66 & -26.43 & -14.81 & -12.60 \\
\hline & Urban & 2.77 & 6.06 & 2.19 & 2.09 & 5.06 & 2.42 & 1.82 & 4.48 & 2.46 & -34.30 & -26.07 & -12.92 & -11.46 \\
\hline & Rural & 3.02 & 6.26 & 2.07 & 2.40 & 5.57 & 2.32 & 2.09 & 4.92 & 2.35 & -30.79 & -21.41 & -12.92 & -11.67 \\
\hline \multicolumn{2}{|c|}{ P-value* } & 0.144 & 0.676 & & 0.045 & 0.314 & & 0.159 & 0.205 & & & & & \\
\hline
\end{tabular}

Statistically significant values bolded $(p<0.05)$

${ }^{a}$ Values were calculated considering a complex sample design

${ }^{b}$ Results from (2012-2000)/2000

c Results from (2012-2006)/2006

${ }^{*} p$-value for t-test 


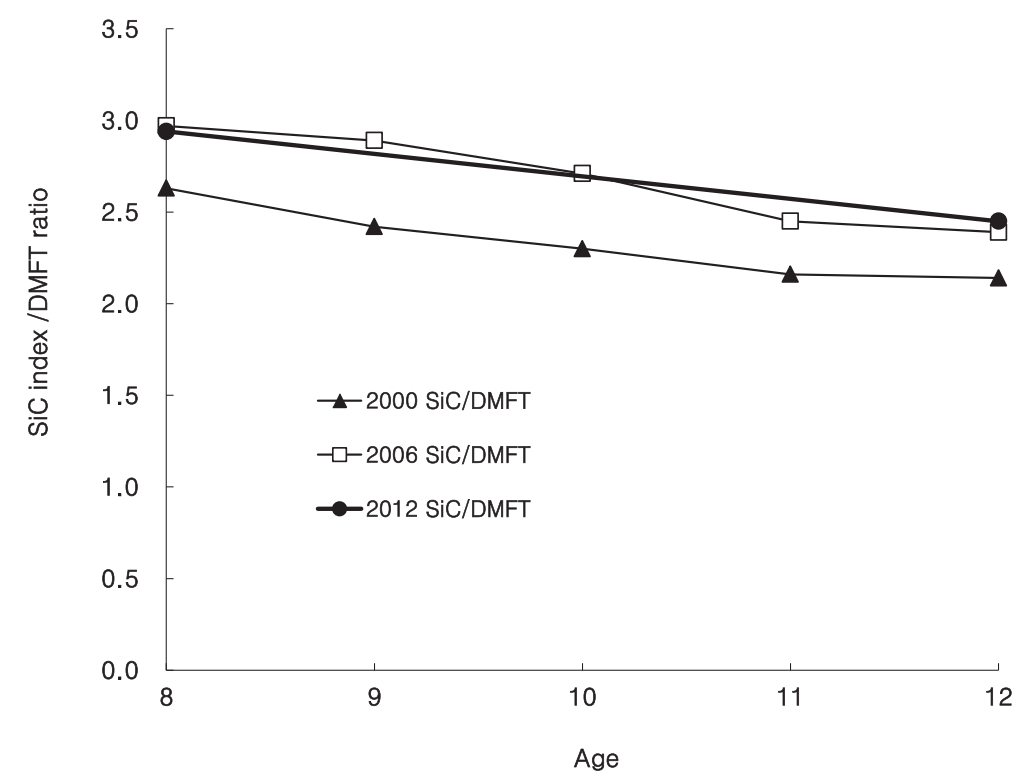

Fig. 1 The relationship expressed by SiC index over DMFT in 2000-2012

and Sweden) where dentists or clinicians worked as chief dental officers compared to their employment in other countries where chief officers in charge of oral health were not dentists or clinicians. It is therefore likely that the Department of Oral Health in the Ministry of Health and Welfare in Korea had played an important role in public oral health.
The percentage of children with fissure-sealed teeth continuously increased between 2000 and 2012. Since the public fissure sealant programme started with the support of the government budget in 2002, more than half of 8-year-old children living in rural areas had sealed teeth in 2006, and the difference in 8-year-old children with sealed teeth between urban and rural areas

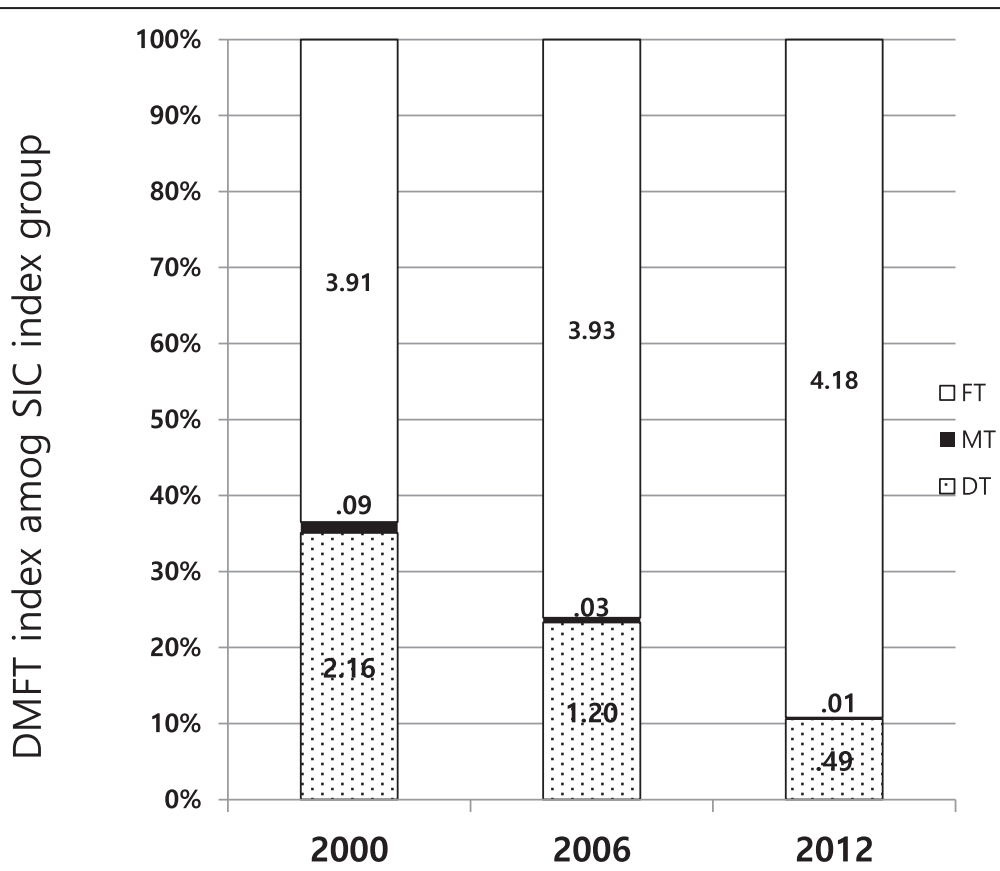

Fig. 2 Mean SiC index in 12-year-old children in Korea, 2000-2012 
was $16.1 \%(p<0.001)$. In rural areas, all children underwent fissure sealant operations without charges; meanwhile, in urban areas, economically disadvantaged children could benefit from the public fissure sealant programme in public health centres without charges. The gaps between the urban and rural areas may have been related to the number of dental hygienists working at public health centres. Dental hygienists have been placed in public health centres located in rural areas since 1986, so they could work for school oral healthcare and public oral educational programmes. After that, the fissure sealant programme was covered by National Health Insurance for children aged 6-14 years in December 2009, but the public free-of-charge fissure sealant programme ceased in 2010; this could have led to the smaller increase in the number of children with sealed teeth in rural, comparatively unprivileged areas. Edelstein and Chinn [34] demonstrated that disparities in dental visits continued to be evidenced by age, family income, race/ethnicity, and caregiver education. Children whose parents did not have enough time to bring children to dental clinics could not benefit from fissure sealant covered by National Health Insurance.

The mean DMFT values of children aged 12 years continuously declined, from 2.86 to 1.84 , over 12 years, which was the first time that the mean DMFT of children aged 12 years was lower than 2.0 since the National Oral Health Survey started in 2000. Cho et al. [35] reported that the mean DMFT scores for 11-year-old children in fluoridated and non-fluoridated areas in 2011 were 1.05 and 1.83, respectively. Despite this decline, the DMFT values of children aged 12 years remains higher than those in other countries. Bernabe and Sheiham [5] reported the DMFT numbers of 12year-olds based on published reports from 26 countries. Among these countries, the DMFT numbers of 12-yearolds in the UK, Finland, Denmark, and Canada were $1.10,0.07,0.89$, and 1.02 , respectively.

Because the $\mathrm{SiC}$ index takes into account the DMFT scores, the $\mathrm{SiC}$ indices also declined with the decrease in mean DMFT scores. The decline gradient for the SiC index was higher than the decline gradient for DMFT scores. Nishi et al. [13] reported that if the total mean DMFT in the whole group decreased by a certain amount, half of the decrease was due to a change in the sub-group used to calculate the $\mathrm{SiC}$ index. The increase in the number of caries-free children and the decrease in $\mathrm{SiC}$ index may have contributed to the overall decline in mean DMFT; however, these do not fully explain the decrease in mean DMFT. In other words, the $\mathrm{SiC}$ index/ DMFT ratio represents the difference between the $\mathrm{SiC}$ index and the DMFT scores of 12 -year-olds. This ratio increased in 2006 compared to that in 2000. However, the ratio in 2012 was similar to that in 2006 and higher than that in 2000. Differences in severity of dental caries still existed, and the gap was worse between 2006 and 2012 than that between 2000 and 2006.

This study confirmed the gradual decline in dental caries among 8- and 12-year-old children between 2000 and 2012. Fluoridated toothpaste was speculated as a potential factor contributing to the decline in dental caries among Korean children. It has been known as the most important reason for the decline in dental caries in developed countries between the 1970s and 1980s [36]. In Korea, almost $97 \%$ of people used fluoridated toothpaste [21]. Lee and Han [30] also demonstrated that the potential determinant of the decline in the number of caries was fluoridated toothpaste. Another use of fluoride for caries prevention was the water fluoridation programme operated in some regions in Korea. Kim et al. [37] assessed the effects of the fluoridation programme on dental caries. The caries preventive fraction was estimated by assessing the differences in DMFT scores. The numbers of DMFT for 12-year-old children in areas with a fluoridation programme and control areas were 1.60 and 2.12, respectively, with an estimated prevention effect of $24.7 \%$.

The main finding of this study was the change in DMFT scores among the sub-group used to calculate the $\mathrm{SiC}$ indices (Fig. 2). The numbers of missing and decayed teeth declined, whereas the number of filled teeth increased between 2000 and 2006. The increased number of filled teeth was the primary factor contributing to the slower decline in DMFT scores. More attention should be given to the fact that coverage of light-curing composite-resin restoration by National Health Insurance in 2018 could influence the number of filled teeth. Jung et al. [19] showed that a significant proportion of the sub-group used to calculate the $\mathrm{SiC}$ index had no sealed fissures on the first molar and lived in rural areas. The public oral health programme to provide fissure sealant by the government budget could be reinforced to reduce the gaps between rural and urban areas. Previous studies reported that significant oral health disparities persist [16, 38, 39]. Patrick et al. [39] reported that children living in poverty are likely to have limited access to dental care, and the improved Medicaid programmes with acceptable reimbursement rates may encourage dentists to treat them.

This study has several limitations, including that we could not consider detailed socioeconomic factors. In the National Oral Health Survey, questionnaires about the parents' socioeconomic factors were collected separately from the oral health data in 2000. Truin et al. [40] reported that the decline in caries in 12-year-olds of low SES has come to an end. However, in medium- and high-SES groups, the percentages of caries-free children have continued to increase, suggesting that the trend in the prevalence of caries could be affected by SES levels. 
Consequently, socioeconomic factors need to be considered in future studies. Oral health is often associated with individual-level determinants, such as oral hygiene and dietary habits. Further research is warranted in order to determine ways to reduce inequalities in oral health among children.

\section{Conclusions}

Although this study lacked information on children's SES and detailed data on individual oral health and diet conditions, a remarkable decline in dental caries for 8and 12-year-old children was observed during the 12year study period. Public oral health programmes using fluoride and fissure sealants and the common use of fluoridated toothpaste may have contributed to the improved oral health of 8- and 12-year-old Korean children. To continue oral health promotion, strategies that support current programmes and coverage for populations with severe dental caries should be considered.

\section{Abbreviations}

DMFT: decayed, missing, and filled teeth; SiC index: Significant Caries index; WHO: World Health Organization; GDP: gross domestic product; SES: socioeconomic status.

\section{Competing interests}

The authors declare that they have no competing interests.

\section{Authors' contributions}

All authors contributed extensively to the work presented in this paper. HK carried out statistical analyses and wrote the manuscript. DH provided the idea for the study. SK and EJ performed the statistical analyses. SJ implemented the literature study design. JK conceived the study, participated in its design and coordination, and helped to draft the manuscript. All authors read and approved the final manuscript.

\section{Acknowledgements}

The results were derived from data from the Korea National Oral Health Survey conducted by the Ministry of Health and Welfare.

\section{Author details}

'Department of Dental Hygiene, College of Health Sciences, Cheongju University, Cheongju, Korea. ${ }^{2}$ Department of Preventive and Social Dentistry, School of Dentistry, Seoul National University, Seoul, Korea. ${ }^{3}$ Department of Preventive and Community Dentistry, Pusan National University, School of Dentistry, 49, Busandaehak-ro, Mulgeum-eup, Yangsan-si, Gyeongsangnam-do, 626-870 Seoul, Korea. ${ }^{4}$ BK Plus Project of Center of Center for Professional Education on Technosciences of Oral Health, Seoul, Korea.

Received: 24 April 2015 Accepted: 2 March 2016

Published online: 22 March 2016

\section{References}

1. Do LG, Spencer A. Oral Health-Related Quality of Life of Children by Dental Caries and Fluorosis Experience. J Public Health Dent. 2007;67:132-9.

2. Sheiham A. Dental caries affects body weight, growth and quality of life in pre-school children. British Dent J. 2006:201:625-6.

3. World Health Organization. Oral health information systems. Oral health surveillance. http://www.who.int/oral health/action/information/ surveillance/en/. Accessed 8 July $201 \overline{5}$.

4. Marthaler T. Changes in the prevalence of dental caries: How much can be attributed to changes in diet? Caries Res. 1990;24 Suppl 1:3-15.
5. Bernabe E, Sheiham A. Extent of differences in dental caries in permanent teeth between childhood and adulthood in 26 countries. Int Dent J. 2014;64:241-5.

6. Piovesan C, Mendes FM, Antunes JLF, Ardenghi TM. Inequalities in the distribution of dental caries among 12-year-old Brazilian schoolchildren. Brazilian Oral Res. 2011;25:69-75.

7. Pine CM, Adair PM, Nicoll AD, Burnside G, Petersen PE, Beighton D, et al. International comparisons of health inequalities in childhood dental caries. Community Dent Health. 2004;21(1 Suppl):121-30.

8. Antunes JLF, Narvai PC, Nugent ZJ. Measuring inequalities in the distribution of dental caries. Community Dent Oral Epidemiol. 2004;32:41-8.

9. Mouradian WE, Wehr E, Crall JJ. Disparities in children's oral health and access to dental care. JAMA. 2000:284:2625-31.

10. Dye BA, Tan S, Smith V, Lewis BG, Barker LK, Thornton-Evans G, et al. Trends in oral health status: United States, 1988-1994 and 1999-2004. Vital Health Stat 11. 2007;248:1-92

11. Ditmyer M, Dounis G, Mobley C, Schwarz E, et al. Inequalities of caries experience in Nevada youth expressed by DMFT index vs. Significant Caries Index (SiC) over time. BMC Oral Health. 2011:11:12.

12. Bratthall D. Introducing the Significant Caries Index together with a proposal for a new global oral health goal for 12-year-olds. Int Dent J. 2000;50:378-84

13. Nishi M, Stjernsward J, Carlsson P, Bratthall D. Caries experience of some countries and areas expressed by the Significant Caries Index. Community Dent Oral Epidemiol. 2002;30:296-301.

14. Reginal Public Health Act. Ministry of Health and Welfare. Oral Health Program. 2015, Ministry of Health and Welfare. 2015, Seoul, Korea. http://law.go.kr/engLsSc.do?menuld=0\&subMenu=5\&query=\#liBgcolor0 Accessed 8 June 2015.

15. Ministry of Health and Welfare. 2000 Guide for Oral Health Program. Seoul: Ministry of Health and Welfare; 2000.

16. Kim CS, Jeon JE. Trends in oral health inequality in 12-year-old Korean children: A study using the Gini coefficient. J Korean Acad Oral Health. 2013;37:154-60

17. Kim MJ, Jun EJ, Han DH, Lee MO, Jeong SH, Kim JB. Oral health status among some disabled person in Jinju. J Korean Acad Oral Health. 2012;36:266-71.

18. Ahn SH, You HY, Kim MJ, Han DH, Kim JB, Jeong SH. Caries preventive effect of permanent teeth using pit and fissure sealant program and community water fluoridation program. J Korean Acad Oral Health. 2012;36:289-96.

19. Jung YS, Jeong SH, Kang NK, Choi YH, Song KB. The characteristics of high caries risk group for 12-years children in Korea. J Korean Acad Oral Health. 2013:37:47-52.

20. Ministry of Health and Welfare. Technical Supporting Organization for water fluoridation. 2000 study for water fluoridation. Ministry of Health and Welfare 2000. Seoul, Korea. http://law.go.kr/engLsSc.do?menuld= 0\&subMenu=5\&query=\#EJP10:0. Accessed 8 June 2015.

21. Kim JY, Lee JH, Kim EK, Kim JB. User rate of fluoride-containing toothpaste in Ulsan metropolitan city. J Korean Acad Oral Health. 2003;27:149-55.

22. Ministry of Health and Welfare. 2000 Korean National Oral Health Survey. Seoul: Ministry of Health and Welfare; 2001. p. 1-4.

23. Dental Health Act by Korea Ministry of Government Legislation. http://law go.kr/engLsSc.do?menuld=0\&subMenu=5\&query=\#liBgcolor0. Accessed 8 June 2015.

24. Korea Health Promotion Foundation. Korea national oral health survey. 2015. http://www.khealth.or.kr. Accessed 20 April 2015

25. Ministry of Health and Welfare. The report of Korean National Oral Health Survey in 2000. Seoul: Ministry of Health and Welfare; 2001

26. Ministry of Health and Welfare. The report of the Korean National Oral Health Survey in 2006. Seoul: Ministry of Health and Welfare; 2007.

27. Ministry of Health and Welfare. The report of Korean National Oral Health Survey in 2012. Seoul: Ministry of Health and Welfare 2013; 12-17. available in Korean at: http://www.mw.go.kr/front_new/jb/sjb030301vw.jsp?PAR_ MENU ID $=03 \&$ MENU ID $=0329 \& C O N T \_S E Q=248179 \&$ page $\left.=1\right]$

28. Han DH, Kim JB, Park DY. The decline in dental caries among children of different ages in Korea, 2000-2006. Int den J. 2010;60:329-35.

29. World Health Organization. Oral health surveys: basic methods. Oral health surveys: basic methods, 1997

30. Lee HJ, Han DH. Exploring the determinants of secular decreases in dental caries among Korean children. Community Dent Oral Epidemiol. 2015:43:357-65. 
31. Park YG, Kim BJ, Han DH, Lee KH, Kim JB. Public health dentistry: Evaluation of caries prevention effect from pit and fissure sealant program added by community water fluoridation program in Habchon-Up, Habcheon-Gun, Korea. J Korean Acad Oral Health. 2008;32:517-27.

32. Kim HB, Kwak. Transition and Economic Growth in Korea. Kor National Eco Ass. 2007;25:125-44

33. Eaton KA, Newman HN, Widström E. A survey of dental hygienist numbers in Canada, the European Economic area, Japan and the United States of America in 1998. British Dent J. 2003;195:595-8.

34. Edelstein BL, Chinn CH. Update on disparities in oral health and access to dental care for America's children. Acad Pediatr. 2009;9:415-9.

35. Cho HJ, Lee HS, Paik DI, Bae KH. Association of dental caries with socioeconomic status in relation to different water fluoridation levels. Community Dent Oral Epidemiol. 2014;42:536-42.

36. Bratthall $D$, Hänsel-Petersson $G$, Sundberg $H$. Reasons for the caries decline: what do the experts believe? Euro J Oral Sciences. 1996;104:416-22.

37. Kim HN, Cho HH, Kim MJ, Jun EJ, Han DH, Jeong SH, Kim JB. Caries Prevention Effect of Water Fluoridation in Gimhae. Korea J Korean Acad Oral Health. 2014;14:448-54.

38. Wamala S, Merlo J, Boström $\mathrm{G}$. Inequity in access to dental care services explains current socioeconomic disparities in oral health: the Swedish National Surveys of Public Health 2004-2005. J Epidemiol Commun Health. 2006;60:1027-33.

39. Patrick DL, Lee RS, Nucci M, Grembowski D, Jolles CZ, Milgrom P. Reducing oral health disparities: a focus on social and cultural determinants. BMC Oral Health. 2006;6 Suppl 1:S4

40. Truin GJ, König KG, Bronkhorst EM, Frankenmolen F, Mulder J, Van't Hof MA. Time trends in caries experience of 6-and 12-year-old children of different socioeconomic status in The Hague. Caries Res. 1997;32:1-4.

\section{Submit your next manuscript to BioMed Central and we will help you at every step:}

- We accept pre-submission inquiries

- Our selector tool helps you to find the most relevant journal

- We provide round the clock customer support

- Convenient online submission

- Thorough peer review

- Inclusion in PubMed and all major indexing services

- Maximum visibility for your research

Submit your manuscript at www.biomedcentral.com/submit 